\title{
Análise da rotulagem de ovos comercializados na cidade do Rio de Janeiro - Brasil
}

\section{Analysis of eggs' labeling marketed in Rio de Janeiro city - Brazil}

\author{
Ismar Araújo de Moraes, ${ }^{\star}$ Sergio Mano, ${ }^{\star \star *}$ Rami Fanticelli Baptista ${ }^{\star \star \star \star}$
}

\begin{abstract}
Resumo
Considerando a importância do consumo de ovos in natura na cidade do Rio de Janeiro, objetivou-se analisar a conformidade das informações contidas na rotulagem das embalagens dos ovos comercializados em supermercados e mercearias, perante a legislação específica brasileira. Foram visitados 21 estabelecimentos na região metropolitana do Rio de Janeiro, sendo identificadas 19 marcas diferentes comercializadas em embalagens contendo seis $(10,5 \%), 10(5,3 \%), 12(68,4 \%)$ ou 360 unidades $(15,8 \%)$. Foi observado que os rótulos de todas as marcas indicaram: a denominação de venda, o conteúdo líquido e a identificação da origem. Entretanto, nem todas as marcas atenderam a recomendação para a correta identificação do lote. A maioria das marcas apresentou, na rotulagem, a data de embalagem $(84,2 \%)$ ou de classificação $(15,8 \%)$ e $94,7 \%$ das marcas apresentaram a data de validade. Apenas uma das marcas apresentou a data de produção impressa na casca do ovo. As informações nutricionais e a cor dos ovos foram observadas em todas as marcas analisadas, mas a tipificação e a classificação foram informadas, respectivamente, em $89,5 \%$ e $26,3 \%$ das mesmas. Em relação ao registro no órgão competente, também se verificou que a totalidade das marcas apresentou esta informação. Destacou-se, também, a dificuldade de um bom entendimento acerca da legislação, que deve ser seguida para a análise da rotulagem. Assim sendo, pode-se concluir que se faz necessário estabelecer regulamentos claros e específicos de modo a facilitar a fiscalização à rotulagem de ovos in natura, de forma a evitar os erros destacados neste estudo e garantindo as informações necessárias para a segurança alimentar, o que é de competência e dever de Estado.
\end{abstract}

Palavras-chave: ovos, rotulagem.

\begin{abstract}
The aim at in this study was to analyze the contained information in the packing labeling of the marketed eggs at supermarkets and grocery stores, in refers to adaptation to specific Brazilian legislation. 21 establishments were visited in the metropolitan area of the city, being identified 19 different marks being marketed in packing with liquid content of six (10.5\%), $10(5.3 \%), 12$ $(68.4 \%)$ or 360 units $(15.8 \%)$. It was observed that all marks indicates the sale denomination, the liquid content and the origin identification, however, nor all the marks assist the recommendation for the correct lot identification. Most of the marks presented preference for informing packing (84.2\%) or classification (15.8\%) date and $94.7 \%$ marks presented validity date. Just one of the marks presented production date printed in shell egg. The nutritional information and the color of the eggs were observed in all analyzed marks, but the type and the class were informed respectively in $89.5 \%$ and $26.3 \%$ of them. In relation to the competent organ registration, it was verified that the totality of the marks presented this information. This study verifies the difficulty of a good understanding concerning the legislation that should be followed for the analysis of the labeling. It can be concluded that it is necessary to establish clear and specific regulations in way to facilitate the labeling fiscalization of shell eggs, avoiding mistakes observed in this study and guaranteeing the necessary information for the alimentary safety, competence and duty of State.
\end{abstract}

Keywords: eggs, labeling.

\section{Introdução}

O "ovo" é o alimento definido pela legislação como sendo aquele proveniente de galinhas e comercializados com casca e, se proveniente de outra ave, deverá conter a informação da sua espécie de origem. Como "ovo fresco" entende-se o ovo em casca que não foi conservado por qualquer processo, perdendo essa denominação de fresco se for submetido intencionalmente a temperaturas inferiores a $8^{\circ} \mathrm{C}$, visto que a temperatura recomendada para armazenamento do ovo fresco está entre $8^{\circ} \mathrm{C}$ e $15^{\circ} \mathrm{C}$ com uma umidade relativa do ar entre 70 e $90 \%$ (Brasil, 1990b).

No processo de comercialização dos ovos a escolha do consumidor se faz pelas informações da rotulagem, e segundo Rossi e Pompei (1995), principalmente pela informação do prazo de validade e da cor dos ovos. Buscando analisar a atitude do consumidor na escolha dos ovos, com

* Departamento de Fisiologia e Farmacologia - Universidade Federal Fluminense - Rua Vital Brazil Filho, 64. Niterói, RJ. 24230-340.

** Superintendência de Controle de Zoonoses, Vigilância e Fiscalização Sanitária (VISA-Rio). Rua do Lavradio, 180. Rio de Janeiro. 20230-070

*** Departamento de Tecnologia de Alimentos. Faculdade de Veterinária - Universidade Federal Fluminense - Niterói, RJ.

**** Universidade do Grande Rio - UNIGRANRIO; Centro Universitário Serra dos Órgãos - UNIFESO.

Autor para correspondência: Ismar Araújo de Moraes. E-mail: fisiovet@vm.uff.br. 
base na sua percepção dos indicativos de boa qualidade do produto, Rodrigues e Saley (2001) evidenciaram equívocos na maioria dos consumidores. Estes autores verificaram que foram apontados, pelos consumidores, como fatores importantes: o tamanho e a cor da casca do ovo, em detrimento da procedência do produto e a sua manutenção à venda sob refrigeração. Outros fatores questionados - prazo de validade, limpeza e integridade da casca e tempo de comercialização foram avaliados corretamente pela maioria dos consumidores.

O monitoramento da rotulagem e dos processos tal como, o controle de qualidade dos produtos são ferramentas que permitem a segurança dos alimentos. Esse monitoramento deve ser uma preocupação dos órgãos de vigilância que contam com instrumentos legais para a prática da fiscalização, e no caso da rotulagem, o controle deve visar torná-los confiáveis e fidedignos (Freitas et al., 2004). Para um melhor entendimento acerca do assunto, a legislação define "rótulo" como sendo toda inscrição, legenda, imagem ou toda matéria descritiva ou gráfica que esteja escrita, impressa, estampada, gravada em relevo ou litografada ou colada sobre a embalagem do alimento. E como "embalagem" o recipiente, o pacote ou o envoltório destinado a garantir a conservação e facilitar o transporte e manuseio dos alimentos (Brasil, 2002).

De acordo com a legislação, as embalagens dos ovos deverão conter as informações quanto à tipificação e classificação (Brasil, 1991). Entende-se por tipificação as condições de cada unidade dentro de um processo de seleção por pesagem, onde seis categorias são determinadas pela
Resolução da Coordenação de Inspeção de Produtos de Origem Animal - CIPOA, nº 005 de 19 de novembro de 1991 (Quadro 1). Por classificação entende-se um processo de seleção baseado na qualidade dos ovos, onde cinco categorias são consideradas: A, B, C, D e E. Essa classificação prescinde da análise laboratorial que é feita por amostragem dentro de cada lote produzido, sendo os critérios classificatórios determinados pela mesma Resolução (Quadro 2). O Regulamento Técnico sobre Rotulagem de Alimentos Embalados (Brasil, 2002), em geral, é aplicável à rotulagem de todo alimento que seja comercializado, qualquer que seja sua origem, embalado na ausência do cliente, e pronto para oferta ao consumidor. De acordo com este regulamento, caso um regulamento técnico específico não determine algo em contrário, a rotulagem de alimentos embalados deve apresentar, obrigatoriamente, as seguintes informações: denominação de venda do alimento, lista de ingredientes, conteúdos líquidos, identificação da origem, nome ou razão social e endereço do importador, no caso de alimentos importados, identificação do lote, prazo de validade, instruções sobre o preparo e uso do alimento, quando necessário. Depreende-se que os ovos in natura não podem ser eximidos da força deste regulamento e deverão fazer contar as exigências previstas aplicáveis.

Em face ao exposto, o objetivo do presente estudo foi identificar as principais marcas de ovos e analisar as condições da rotulagem contida nas embalagens dos ovos mais frequentemente comercializados na cidade do Rio de Janeiro no que se refere às normas estabelecidas na legislação vigente.

Quadro 1: Tipos de ovos e parâmetros a serem considerados para a tipificação de ovos

\begin{tabular}{|l|l|}
\hline Tipificação do ovo & $\begin{array}{c}\text { Parâmetros considerados } \\
\text { (peso, g/unidade) }\end{array}$ \\
\hline Tipo 1 (jumbo) & mínimo acima de 66 \\
\hline Tipo 2 (extra) & entre 60-65 \\
\hline Tipo 3 (grande) & mínimo entre 55-60 \\
\hline Tipo 4 (médio) & mínimo entre 50-55 \\
\hline Tipo 5 (pequeno) & mínimo entre 45-50 \\
\hline Tipo 6 (industrial) & abaixo de 45 \\
\hline
\end{tabular}

Fonte: Resolução CIPOA no 005 de 19 de novembro de 1991 (Brasil, 1991), modificado pelos autores

Quadro 2: Classificação de ovos e parâmetros considerados

\begin{tabular}{|c|c|c|c|c|}
\hline CLASSE & CASCA & CÂMARA DE AR & ALBÚMEN & GEMA \\
\hline A & $\begin{array}{c}\text { Limpa } \\
\text { Íntegra } \\
\text { Sem deformação }\end{array}$ & $\begin{array}{l}\text { Fixa } \\
\text { Máx. } 4 \mathrm{~mm}\end{array}$ & $\begin{array}{c}\text { Límpido } \\
\text { Transparente } \\
\text { Consistente } \\
\text { Calazas íntegras }\end{array}$ & $\begin{array}{c}\text { Translúcida } \\
\text { Consistente } \\
\text { Centralizada } \\
\text { S/ desenvolvimento do germe }\end{array}$ \\
\hline B & $\begin{array}{c}\text { Limpa } \\
\text { Íntegra } \\
\text { Ligeira deformação } \\
\text { Discretamente manchada }\end{array}$ & $\begin{array}{l}\text { Fixa } \\
\text { Máx. } 6 \mathrm{~mm}\end{array}$ & $\begin{array}{c}\text { Límpido } \\
\text { Transparente } \\
\text { Relativamente } \\
\text { consistente } \\
\text { Calazas íntegras }\end{array}$ & $\begin{array}{c}\text { Ligeiramente descentralizada e } \\
\text { deformada } \\
\text { Contorno definido } \\
\text { S/ desenvolvimento do germe }\end{array}$ \\
\hline C & $\begin{array}{c}\text { Limpa } \\
\text { Íntegra } \\
\text { Defeito de textura e contorno } \\
\text { Manchada }\end{array}$ & $\begin{array}{l}\text { Solta } \\
\text { Máx. } 10 \mathrm{~mm}\end{array}$ & $\begin{array}{l}\text { Ligeiramente turvo } \\
\text { Relativamente } \\
\text { consistente } \\
\text { Calazas íntegras }\end{array}$ & $\begin{array}{l}\text { Descentralizada e deformada } \\
\text { Contorno definido } \\
\text { S/ desenvolvimento do germe }\end{array}$ \\
\hline D & \multicolumn{4}{|c|}{ Ovo Sujo - Não quebrada, com sujeira ou material externo aderente, manchas moderadas. } \\
\hline E & \multicolumn{4}{|c|}{$\begin{array}{l}\text { Ovo Trincado - Com casca quebrada ou rachada, mas cujas membranas da casca estejam intactas e cujo } \\
\text { conteúdo não vaze. }\end{array}$} \\
\hline
\end{tabular}

Fonte: Resolução CIPOA no 005 de 19 de novembro de 1991 (Brasil, 1991), modificado pelos autores 


\section{Material e métodos}

Foram visitados 21 estabelecimentos caracterizados como supermercados, localizados na área metropolitana da cidade do Rio de Janeiro com vistas a identificar as diferentes marcas de ovos em comercialização e registrar as informações contidas na rotulagem.

Durante as visitas foram preenchidas 46 fichas previamente preparadas contendo campos próprios para identificação da firma revendedora, marca do ovo, tipo de embalagem utilizada, quantidade de ovos por embalagem, data de embalagem, data de classificação, classificação indicada, data de produção, data de validade, presença de informações nutricionais, número de registro de pessoa física ou jurídica, identificação e número de registro no órgão competente, existência de instruções ou modo de conservação, número de registro do rótulo do produto e informações contidas na própria casca do ovo.

A coleta dos dados ocorreu entre os meses de janeiro e março de 2005. Após a coleta das informações, os dados foram totalizados e analisados buscando verificar a adequação dentro do estabelecido no Regulamento da Inspeção Industrial e Sanitária de Produtos de Origem Animal - RIISPOA (Brasil 1997), na Portaria nº 01, editada pelo Ministério da Agricultura em 1990 (Brasil, 1990b) e na Resolução RDC no 259, de 20 de setembro de 2002 (Brasil, 2002).

A análise estatística constou de uma análise descritiva simples, onde se realizou a média e proporção dos diversos dados estudados, realizando-se um estudo comparativo, com utilização de tabelas e gráficos. Para a realização da referida análise estatística descritiva e confecção dos gráficos utilizouse o programa Microsoft Excel.

\section{Resultados}

A análise das planilhas preenchidas permitiu identificar 19 marcas diferentes de ovos in natura, sendo comercializadas nos supermercados da cidade do Rio de Janeiro. Dentre as marcas, observou-se que é comum a venda em embalagens onde os ovos são acondiconados em polpa de celulose moldada (colmeias), confeccionadas em papelão $(52,6 \%)$, plástico transparente $(31,6 \%)$ ou poliestireno expandido $(15,8 \%)$, as quais podem conter seis $(10,5 \%)$, dez $(5,3 \%)$ ou $12(68,4 \%)$ ovos, também podendo ser encontrados em caixas contendo 30 dúzias do produto (15,8\%). A informação, quanto ao conteúdo líquido da embalagem, foi observada em todas as marcas analisadas.

O grupo (cor) a que pertencem os ovos foi informado em todas as embalagens analisadas. A cor branca foi observada em $63,2 \%$ das marcas, enquanto a vermelha em somente $36,8 \%$ destas.

A declaração da tipificação obtida pelo ovo conforme estabelecido pela legislação foi observada em $89,5 \%$ das marcas. Foi observada a venda de ovos tipificados como "extra" (31,6\%), "grande" (47,4\%) e "médio" (10,5\%), sendo esta última proporção observada em marcas onde a tipificação não foi informada. Ovos tipificados como "jumbo", "pequenos" e "industrial" não foram encontrados. No que se refere à informação sobre a classificação também prevista na lei, observou-se que somente cinco $(26,3 \%)$ marcas identificaram a classe "A" para seus produtos. As demais marcas (73,7\%) não apresentaram essa informação em suas embalagens.

Quanto à declaração das datas de: produção, classificação e embalagem, foi observado que a maioria das indústrias produtoras tem, por preferência, informar somente a data de embalagem $(84,2 \%)$ em detrimento das demais datas. Uma única marca apresentou a data de produção, sendo que esta era coincidente com a data de embalagem também informada. Apenas três marcas $(15,8 \%)$ preferiram apresentar a data de classificação; no entanto, apenas uma destas marcas informou a classificação do seu produto na embalagem.

No que se refere à data de validade, foi observado que a grande maioria $(94,7 \%)$ declarou esta informação em seus rótulos. Apenas uma (5,3\%) exceção foi observada quanto a este critério.

\section{Discussão}

Informações simples e inequívocas devem ser entendidas como um direito fundamental do consumidor (Brasil, 1990a) e estas devem estar reguladas pelo poder público. Neste aspecto, as legislações que julgamos afetas à comercialização dos ovos e vigendo no Brasil são a RDC 259/2002 da Anvisa (Brasil, 2002 ) que legisla sobre a rotulagem dos produtos alimentares em geral e a Portaria $n^{\circ}$ 01/1990 do Ministério da Agricultura (Brasil, 1990b). Ainda deve ser considerado o RIISPOA (Brasil, 1997) que, ao estabelecer as normas a serem seguidas nas unidades de produção, acabam indicando condições que deveriam ser observadas na etapa de comercialização dos mesmos.

Buscando observar o que prevê o RIISPOA (Brasil, 1997), foi constatado que não existem marcas no comércio comercializando ovos com carimbo do Serviço de Inspeção Sanitária (SIF) no pólo maior do ovo conforme determina o seu artigo 826, tampouco foi observada a etiqueta modelo 8 prevista neste mesmo artigo para as situações em que o ovo não é carimbado. Se esta obrigatoriedade foi extinguida por regulamento posterior, esse dispositivo não foi encontrado na literatura compulsada.

Considerando a matéria legislada na RDC 259/2002 (Brasil, 2002) relativa à rotulagem dos produtos alimentares em geral, observou-se que todas as marcas indicam a informação "ovo" como denominação de venda, e que o conteúdo líquido e a identificação da origem também estão sempre presentes. Entretanto, nem todas as marcas atendem à recomendação para a correta identificação de seu lote. Na maioria das vezes, no local indicado na embalagem para informação sobre o lote, é encontrada a data de embalagem ou classificação. Essa prática é comum em muitos dos alimentos que são encontrados no comércio e deve-se à RDC 259/2002, que estabelece que todo rótulo deva ter impresso, gravado ou marcado de qualquer outro modo, uma indicação em código ou linguagem clara, que permita identificar o lote a que pertence o alimento, de forma que seja visível, legível e indelével, mas permite que a indicação do lote seja feita por um código-chave precedido da letra "L", o qual deverá estar à disposição da autoridade competente; ou utilizar a data de fabricação, embalagem ou de prazo de validade para tal, sempre que a(s) mesma(s) indique(m), pelo menos, o dia e o mês ou o mês e o ano. 
Uma correta identificação do lote permite a rastreabilidade do alimento em casos de agravos à saúde e deveria contar com critérios tão rigorosos quanto aqueles considerados nos estudos dos circuitos de distribuição de alimentos, com vistas à identificação de todas as fases de sua comercialização, considerado como condição primordial para a concepção e implementação de políticas governamentais na área de segurança alimentar por Scarborough e Kydd (1992) apud Rodrigues e Saley (2001).

No caso do comércio de ovos, este estudo demonstrou que a data de produção quase nunca é informada sendo preferencial a informação da data de embalagem ou de classificação. Sobre quantos dias são transcorridos desde a oviposição até a embalagem ou classificação não se pode precisar com base nas informações disponíveis na rotulagem e, para este critério, não observamos instruções em lei. Apenas uma das marcas apresentou a data de produção impressa na casca do ovo. Entendemos que esta condição, ainda que não prevista na legislação, deveria ser estimulada, pois parece um método eficiente para o controle das fraudes no comércio, além de ser, também, um bom diferenciador para o consumidor que acondiciona uma nova remessa, recém-adquirida, juntamente aos armazenados no domicílio.

No que se refere à data de validade, foi observado que a grande maioria $(94,7 \%)$ declarou essa informação em seus rótulos. Entendemos que esta informação, além de critério estabelecido em lei, conta com cultura já desenvolvida por parte do público consumidor, conforme já foi demonstrado por Rodrigues e Saley (2001) e acaba por ser considerada indispensável pelos fornecedores que buscam atender às expectativas do público consumidor por razões, na maioria das vezes, estritamente econômicas. Como exemplo disto, a tipificação que indica denominações de tamanho do ovo e são de fácil entendimento pelo público, são mais freqüentes na rotulagem do que a classificação que indica o real critério da qualidade do ovo. Observe-se que, neste estudo, 73,7\% das marcas não apresentaram essa informação importante em suas embalagens, desrespeitando a legislação e o público consumidor leigo.

As informações nutricionais foram observadas em todas as marcas analisadas. Entretanto, considerando que a legislação relativa à rotulagem nutricional vem, nos últimos anos, sofrendo mudanças nas suas exigências e sucessivas prorrogações de prazo para sua completa vigência, não foram realizados comentários a respeito de sua adequação à legislação que, no momento, conta com instruções em duas resoluções conjuntas da diretoria colegiada da ANVISA: a RDC 359 (Brasil, 2003) e a RDC 360 (Brasil, 2003a). O prazo para cumprimento das exigências previstas nestas resoluções já expiraram desde 31 de julho de 2006, mas a mesma ANVISA publicou a Resolução RE no 2313 em 26 de julho de 2006 (Brasil, 2006) determinado que as empresas tivessem até o dia 1 de janeiro de 2007 para o cumprimento de todas as exigências.

\section{Referências}

BRASIL. Congresso Nacional. Lei nº 8078, de 11 de setembro de 1990. Dispõe sobre a Proteção do Consumidor e dá outras Providências. Diário Oficial da União - D.O.U.; Poder Executivo, de 12 de setembro de 1990. 1990a.
Em relação ao registro no órgão competente, também se verificou que a totalidade das marcas apresentou esta informação, ainda que não se tenha buscado verificar a autenticidade dos registros, todas as marcas encontram-se adequadas à lei.

A constatação de que nos supermercados da cidade do Rio de Janeiro a maioria das embalagens de ovos apresentava conteúdo líquido de 12 ovos parece indicar ser esta a preferência do consumidor e demonstra o comportamento tradicional do mercado de ovos em apresentar e comercializar em dúzias. As caixas de 30 dúzias observadas neste estudo tinham, por destino principal, a venda dos ovos na forma "a granel", o que consideramos como prática perigosa, pois as informações da rotulagem não são repassadas ao público consumidor. Quando ocorre o fracionamento do produto, na maioria das vezes, conforme já observou Marins et al. (2005), é comum a omissão dos dados obrigatórios na rotulagem que foi, inclusive, justificada pelas dificuldades encontradas pelas indústrias e estabelecimentos comerciais diante da falta de orientação técnica por parte dos órgãos competentes e legisladores.

A falta de regulamentos claros acerca da rotulagem de ovos foi uma dificuldade encontrada para discutir o assunto. Como exemplo, não foi possível identificar a quem exatamente cabe instruir e aprovar a rotulagem do ovos in natura. De acordo com a Portaria 01 (Brasil, 1990b), a inspeção de ovos pela instância federal deverá incidir sobre a verificação das condições de embalagem, tendo em vista sua limpeza, mau cheiro por ovos anteriormente quebrados ou por qualquer outra causa, além da apreciação geral do estado de limpeza e integridade da casca e da partida em conjunto. Não é feita qualquer referência acerca de sua competência para fazer constar informações obrigatórias na rotulagem. Dessa forma, o produto atinge o mercado sem as devidas correções, e resta, em última instância, que as vigilâncias de nível estadual ou municipal se encarreguem de coletar amostras, identificar o problema e atuar junto às indústrias no sentido de proceder às correções, um fato que, pelo observado, não vem ocorrendo.

De todo o exposto, pode-se concluir que as informações presentes nas embalagens de ovos são, em sua maioria, deficientes ou mesmo equivocadas, destacando-se a dificuldade, por parte do produtor, de um bom entendimento acerca da legislação, que deve ser seguida para a realização da rotulagem. Sugere-se, portanto, a formulação de regulamentos claros e específicos de modo a facilitar a fiscalização relativa à rotulagem de ovos in natura, os quais deverão ser verificados desde a indústria até a comercialização, garantindo, assim, alimentos dentro das normas sanitárias e facilitando a escolha acertada por parte do consumidor. Sugere-se, também, a implementação de campanhas de cunho educativo visando informar e sensibilizar os consumidores e os agentes da cadeia produtiva em relação à qualidade sanitária do ovo in natura.

BRASIL. Ministério da Agricultura e do Abastecimento. Secretaria de Defesa Agropecuária. Divisão de Inspeção de Carnes e Derivados DICAR. Portaria n 01, de 21 de Fevereiro de 1990. Normas Gerais de Inspeção de Ovos e Derivados. Diário Oficial da republica Federativa do Brasil, Brasília, DF, n. 44, p. 4321, 6 mar. 1990b. 
BRASIL. Ministério da Agricultura e do Abastecimento. Secretaria de Defesa Agropecuária. Divisão de Inspeção de Carnes e Derivados DICAR. Resolução 005 de 19/11/91 da Coordenação de Inspeção de Produtos de Origem Animal - CIPOA. 1991.

BRASIL. Ministério da Agricultura e do Abastecimento. Secretaria de Defesa Agropecuária. Departamento de Inspeção de Produtos de Origem Animal - DIPOA. Regulamento da Inspeção Industrial e Sanitária de Produtos de Origem Animal (RIISPOA). Aprovado pelo Decreto n. 30.691, 29/03/52, alterado pelos Decretos no 1255 de 25/ 06/62, 1236 de 02/09/94, 1812 de 08/02/96 e 2244 de 04/06/97. Brasília, DF, 1997.

BRASIL. Ministério da Saúde. Agência Nacional de Vigilância Sanitária ANVISA. Resolução-RDC no 259, de 20 de setembro de 2002 Aprova o Regulamento Técnico sobre Rotulagem de Alimentos Embalados. Diário Oficial da União; Poder Executivo, de 23 de setembro de 2002.

BRASIL, Ministério da Saúde. Agência Nacional de Vigilância Sanitária - ANVISA. Resolução RDC no 359, de 23 de dezembro de 2003. Aprova Regulamento Técnico de Porções de Alimentos Embalados para Fins de Rotulagem Nutricional. Diário Oficial da União; Poder Executivo, de 26 de dezembro de 2003.

BRASIL. Ministério da Saúde. Agência Nacional de Vigilância Sanitária - ANVISA. Resolução RDC nํ360, de 23 de dezembro de 2003. Aprova Regulamento Técnico sobre Rotulagem Nutricional de Alimentos
Embalados, tornando obrigatória a rotulagem nutricional. Diário Oficial da União; Poder Executivo, de 26 de dezembro de 2003.

BRASIL. Ministério da Saúde. Agência Nacional de Vigilância Sanitária - ANVISA. Resolução RE no 2313, de 26 de julho de 2006. Determina a publicação de: "Procedimentos a serem observados para a implementação das Resoluções de Diretoria Colegiada RDC no.s. 359 e 360, de 2003'. Diário Oficial da União; Poder Executivo, de 27 de julho de 2006.

FREITAS, J.S.; DAMASCENO, K.S.F.S.C.; CALADO, C.L.A. Rotulagem de alimentos lácteos: a percepção do consumidor. Higiene Alimentar, v. 18, n. 125, p. 17-23. 2004.

MARINS, B.R.; JACOB, S.C.; TANCREDI, R.C.P. A rotulagem de alimentos praticada pelo estabelecimento fracionador. Será que obedece a legislação vigente? Higiene Alimentar, v. 19, n. 137, p. 121-126, 2005. RODRIGUES, K.R.M.; SALEY, E. Atitudes de granjeiros, atacadistas, varejistas e consumidores em relação à qualidade sanitária do ovo de galinha in natura. Revista de Nutrição, v. 14, n. 3, p. 185-193, 2001. ROSSI, M.; POMPEI, C. Changes in some egg components and analytical values due to hen age. Poultry Science, v. 74, p. 152-160, 1995.

SCARBOROUGH, V., KYDD, J. Economic analysis of agricultural markets: a manual. Chatmam: Natural Resouces Institute, 1992.166 p. (Marketing Series, v. 5). 